\title{
Safety and Efficacy of Ripasudil in Japanese Patients with Glaucoma or Ocular Hypertension: 3-month Interim Analysis of ROCK-J, a Post-Marketing Surveillance Study
}

\author{
Hidenobu Tanihara - Takahiko Kakuda - Tetsuro Sano • \\ Takashi Kanno $\cdot$ Ryosuke Imada $\cdot$ Wataru Shingaki $\cdot$ Ryoji Gunji
}

Received: November 16, 2018 / Published online: January 4, 2019

(C) The Author(s) 2019

\section{ABSTRACT}

Introduction: To evaluate the safety and intraocular pressure (IOP)-lowering effects of a ripasudil $0.4 \%$ ophthalmic solution in Japanese patients with glaucoma and ocular hypertension $(\mathrm{OH})$ as a post-marketing surveillance.

Methods: This was a 2-year prospective observational study in patients with glaucoma or $\mathrm{OH}$ who had not previously received ripasudil. Patients registered in the study using a central internet-based system from June 1, 2015 to April 30, 2017. Data on adverse drug reactions (ADRs) and IOP were collected and analysed from the first 3 months of ripasudil treatment. Results: Of the 3058 patients in the safety analysis set, 3016 had IOP data and were included in the efficacy analysis. ADRs were seen in $244(8.0 \%)$ of the 3058 patients. IOP decreased significantly in patients with primary open-angle glaucoma $(-2.9 \pm 4.2 \mathrm{mmHg}$; $p<0.001)$, normal tension glaucoma

Enhanced digital features To view enhanced digital features for this article go to https://doi.org/10.6084/ m9.figshare.7478348.

H. Tanihara $(\bowtie)$

Kumamoto University Hospital, Kumamoto, Japan e-mail: tanihara@pearl.ocn.ne.jp

T. Kakuda · T. Sano · T. Kanno · R. Imada · W. Shingaki · R. Gunji

Post Marketing Surveillance Department, Kowa

Company, Ltd., Tokyo, Japan
$(-1.7 \pm 2.4 \mathrm{mmHg} ; p<0.001)$, primary angleclosure glaucoma $(-3.9 \pm 5.3 \mathrm{mmHg} ; \quad p<$ $0.001)$, and $\mathrm{OH}(-3.8 \pm 5.8 \mathrm{mmHg} ; p<0.001)$. Significant IOP reduction was also noted in exfoliation glaucoma $(-3.0 \pm 5.5 \mathrm{mmHg}$; $p<0.001)$, uveitis-associated glaucoma $(-4.7 \pm$ $7.2 \mathrm{mmHg} ; p<0.001)$ and steroid glaucoma $(-5.5 \pm 6.0 \mathrm{mmHg} ; \quad p<0.001)$, but not for neovascular glaucoma $(-2.8 \pm 12.1 \mathrm{mmHg}$; $p=0.669)$.

Conclusion: Ripasudil was safe and effective in the treatment of glaucoma and $\mathrm{OH}$ in Japanese patients, with a low incidence of ADRs or treatment discontinuation, and reduced IOP after 3 months of treatment.

Funding: Kowa Company, Ltd., Tokyo, Japan.

Keywords: Efficacy; Glaucoma; Intraocular pressure; Observational study; Ophthalmology; Post-marketing surveillance; Ripasudil; ROCK inhibitor; Safety

\section{INTRODUCTION}

Glaucoma is an ocular condition characterized by functional and structural abnormalities of the optic nerve related to retinal ganglion cell death $[1,2]$. It is the second leading cause of irreversible blindness in the world [3]. The risk factors for the onset and progression of glaucoma are reported to be age, ethnicity, family history, myopia of a higher degree and 
increased intraocular pressure (IOP) [4]. Since elevated IOP is one of the main risk factors for the onset and progression of glaucoma, lowering IOP has been regarded as the main strategy for treatment to prevent loss of vision in glaucomatous patients $[5,6]$. Currently used modalities for glaucoma include medical, laser and surgical therapies [4]. Prostaglandin analogues and beta-blockers are used as first-line medical treatment of glaucoma, followed by local carbonic anhydrase inhibitors, and alphaagonists [7].

Recently, in addition to the aforementioned IOP-lowering drugs, Rho-associated protein kinase (ROCK) inhibitors have been developed to reduce IOP in animal and human eyes [8-10]. The IOP-lowering effects of ROCK inhibitors change the status of trabecular meshworks and Schlemm's canal endothelial cells, resulting in improvement in the conventional aqueous outflow. Because these novel IOP-lowering mechanisms are different from the mechanisms of other anti-glaucoma medications, ROCK inhibitors have received much attention from investigators.

Ripasudil (Glanatec ${ }^{\circledR}$ ophthalmic solution 0.4\%; Kowa Company, Ltd., Japan) was approved for the treatment of glaucoma and ocular hypertension $(\mathrm{OH})$ for the first time in September 2014 [11-13]. Ripasudil has demonstrated IOP-lowering effects when used as monotherapy or in combination with prostaglandin analogues or beta-blockers [14-18]. In addition, ripasudil has an acceptable safety profile with conjunctival hyperemia, conjunctivitis and blepharitis as adverse drug reactions (ADRs) [14-18]. However, long-term analysis (longer than 1 year) of the safety and efficacy profile has been far from satisfactory. Additionally, previous reports have included only small case series on the IOP-lowering effects of ripasudil for secondary glaucoma (SG).

Thus, this large-scale post-marketing surveillance study was conducted in an attempt to evaluate the safety and efficacy of ripasudil in patients with glaucoma (including SG) or $\mathrm{OH}$ over 2 years. The current interim analysis describes the results from the first 3 months of the 2-year treatment period with the aim of providing information on ripasudil in the early post-marketing period.

\section{METHODS}

\section{Study Design and Patients}

This study, the Ripasudil Observational study to Confirm the safety and efficacy of Rho Kinase inhibitor for long-term use in Japanese patients with glaucoma (ROCK-J), is an ongoing prospective, multicentre, open-label, post-marketing study investigating the safety and efficacy of ripasudil in patients with glaucoma or $\mathrm{OH}$. The total surveillance period for this study is from June 1, 2015 to February 29, 2020. The case registration period was from June 1, 2015 to April 30, 2017 during which patients registered in the trial using an internet-based central registration system. The observation period is 2 years after initiation of ripasudil treatment. This interim analysis included data from 3 months after initiation of ripasudil treatment in patients seen at 621 hospitals and clinics in Japan.

Patients were eligible to participate if they had glaucoma or $\mathrm{OH}$, were unable to receive or responded poorly to other glaucoma medicines, had not previously received ripasudil treatment, had IOP measured before the start of ripasudil treatment, and registered for the study within 14 days of ripasudil initiation. All patients were observed after initiation of ripasudil treatment, and patient information was collected using an electronic case record form collection system. The data of interest included patient background, ripasudil treatment status, concomitant medication status, ocular surgery status, ophthalmic parameters (e.g. IOP, visual field and corrected visual acuity) and ADRs.

The main outcome measures were the proportion of patients with ADRs, which were classified according to the International Conference on Harmonisation Medical Dictionary for Regulatory Activities Japanese edition (MedDRA/J) Version 19.1, and the mean change in IOP from baseline to the last observation. Only one eye was evaluated in each patient to determine IOP in cases where ripasudil was 
administered to both eyes. The eye with the highest IOP at baseline was selected for evaluation, or if the two eyes had the same IOP at baseline, the right eye was selected for evaluation. The analysis excluded data from patients who changed to other glaucoma medicine or underwent intraocular surgery after ripasudil was started.

Treatment initiation patterns with ripasudil were classified into the following five groups based on previous and concomitant drug information: "Add-on (only)", added ripasudil alone to their ongoing treatment with another glaucoma medicine; "Add-on (with other glaucoma drug)", added ripasudil and another glaucoma medicine simultaneously to their ongoing treatment with another glaucoma medicine; "Switch from prior treatment", switched to ripasudil from prior treatment; "Initial monotherapy", initiated ripasudil monotherapy as their first glaucoma treatment; and "Initial combination therapy", started their first glaucoma treatment with ripasudil in conjunction with another glaucoma medicine.

The study was conducted in accordance with relevant regulations in Japan (Ministerial Ordinance on Good Post-Marketing Study Practice, Ministry of Health, Labour and Welfare Ordinance Number 171, December 20, 2004). The study protocol was reviewed and approved by the Japanese regulatory authority prior to study initiation. The study did not undergo review by the ethics committee of the participating medical institutions or procedures for informed consent as this was not required for post-marketing surveillance studies according to Japanese regulations.

\section{Statistical Analysis}

All patients were included in the safety analysis except those who did not return to the clinic or hospital after the start of ripasudil treatment. Patients in the safety analysis set with IOP data available after the start of ripasudil treatment were included in the efficacy analysis.

Statistical analyses were conducted using SAS Version 9.3 (SAS Institute, Japan). Descriptive statistics [number of patients, mean and standard deviation (SD)] were used to summarize continuous efficacy variables, and frequency and percentage were used to describe categorical safety and efficacy variables. A onesample $t$ test was used to calculate the mean change in IOP from baseline, with a significance level set at 5\% (two tailed).

\section{RESULTS}

\section{Patient Disposition and Characteristics}

Overall, 3459 patients were registered in the post-marking surveillance study. Of the 3111 patients whose case record forms were available, 53 patients failed to return to the clinic after initiation of ripasudil treatment, and 3058 patients were included in the safety analysis set. The efficacy analysis set included the 3016 eyes (patients) with IOP data available after ripasudil initiation (Fig. 1).

Of the 3058 patients included in the safety analysis set, approximately half of the patients were male (47.9\%) and the mean \pm SD age was $69.1 \pm 12.7$ years. Primary open-angle glaucoma (POAG, 45.4\%) was the most common diagnosis, followed by normal tension glaucoma (NTG, 36.9\%), secondary glaucoma (SG, $9.1 \%), \mathrm{OH}(4.1 \%)$ and primary angle-closure glaucoma (PACG, 2.1\%; Table 1). SG consisted primarily of exfoliation glaucoma (4.2\%), glaucoma secondary to uveitis $(1.6 \%)$, steroid glaucoma $(0.9 \%)$ and neovascular glaucoma $(0.8 \%)$.

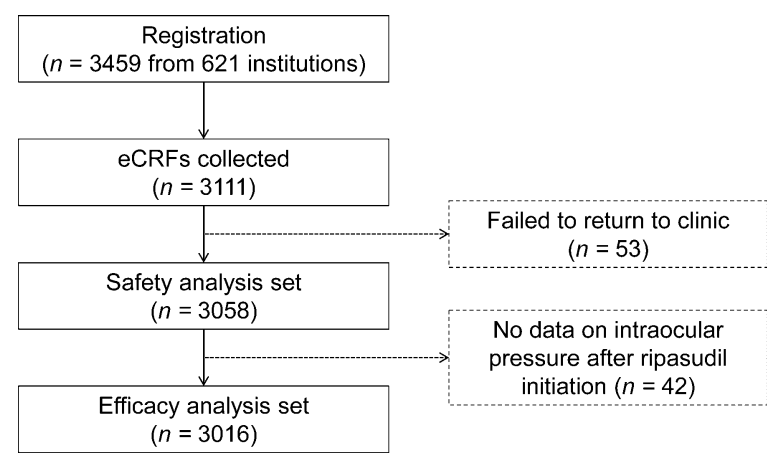

Fig. 1 Patient flow. eCRF electronic case report form 
Table 1 Baseline characteristics of patients

\begin{tabular}{|c|c|}
\hline Characteristics & $n(\%)$ \\
\hline No. of patients analysed & $3058(100.0)$ \\
\hline \multicolumn{2}{|l|}{ Sex } \\
\hline Male & $1466(47.9)$ \\
\hline Female & $1592(52.1)$ \\
\hline \multicolumn{2}{|l|}{ Age, years } \\
\hline$<65$ years & $909(29.7)$ \\
\hline$\geq 65$ years & $2149(70.3)$ \\
\hline Mean $\pm S D$ & $69.1 \pm 12.7$ \\
\hline \multicolumn{2}{|l|}{ Diagnosis } \\
\hline Ocular hypertension & $124(4.1)$ \\
\hline Primary open angle glaucoma & $1389(45.4)$ \\
\hline Normal tension glaucoma & $1128(36.9)$ \\
\hline Secondary glaucoma & $277(9.1)$ \\
\hline Exfoliation glaucoma & $129(4.2)$ \\
\hline Uveitis-associated glaucoma & $50(1.6)$ \\
\hline Steroid glaucoma & $26(0.9)$ \\
\hline Neovascular glaucoma & $24(0.8)$ \\
\hline Primary angle-closure glaucoma & $64(2.1)$ \\
\hline Childhood glaucoma & $3(0.1)$ \\
\hline Others & $73(1.4)$ \\
\hline
\end{tabular}

$S D$ standard deviation

\section{Treatment Initiation Patterns with Ripasudil}

In the 3016 eyes (patients) included in the efficacy analysis, the numbers of patients classified as "Add-on (only)", "Add-on (with other glaucoma drug)", "Switch from prior treatment", "Initial monotherapy" and "Initial combination therapy" were $2482(82.3 \%), 57$ (1.9\%), 97 (3.2\%), $326(10.8 \%)$ and $54(1.8 \%)$, respectively. The mean \pm SD number of glaucoma medicines concomitantly used by patients was $2.3 \pm 1.0$.

\section{Safety}

In the 3058 patients included in the safety analysis set, the mean \pm SD observation period was $95.6 \pm 26.5$ days for this 3-month interim study. In $244(8.0 \%)$ of the 3058 patients, at least one ADR was noted (Table 2). A total of 284 ADRs were reported, and the most common ADRs were conjunctival and ocular hyperemia ( $n=122 ; 4.0 \%)$; conjunctivitis, including allergic conjunctivitis $(n=42 ; 1.4 \%)$; blepharitis, including allergic blepharitis $(n=24 ; 0.8 \%)$; eye pruritus $(n=15 ; 0.5 \%)$ and punctate keratitis $(n=14 ; 0.5 \%)$. ADRs affecting other physiological systems were rare and did not occur in more than five patients.

Ripasudil treatment was discontinued in 277 $(9.1 \%)$ of the 3058 patients. In 115 (3.8\%) of the 277 patients, onset of an ADR was the reason for the discontinuation of ripasudil. Other reasons for the discontinuation of ripasudil were poor response $(n=66 ; 2.2 \%)$, discontinuation of clinic visits/referral $(n=47 ; 1.5 \%)$, request from patients $(n=35 ; 1.1 \%)$, favourable course of IOP $(n=10 ; 0.3 \%)$ and other reasons $(n=4$; $0.1 \%)$.

\section{Efficacy}

In all 2839 eyes (without discontinuation of ripasudil treatment) included in the efficacy analysis, after ripasudil treatment, the mean IOP change from the baseline was $-2.6 \pm 4.1 \mathrm{mmHg}$, showing a statistically significant difference $(p<0.001) \quad$ (Fig. 2). The mean IOP reduction was $-3.8 \pm 5.8 \mathrm{mmHg}$ in 114 eyes with $\mathrm{OH}(p<0.001),-2.9 \pm 4.2$ in 1315 eyes with POAG $(p<0.001),-1.7 \pm 2.4$ in 1092 eyes with NTG $(p<0.001),-3.9 \pm 5.3$ in 54 eyes with PACG $(p<0.001)$ and $-3.7 \pm 6.6$ in 255 eyes with SG $(p<0.001)$.

Of the 255 patients with SG, significant IOP reduction was observed in patients with exfoliation glaucoma, uveitis-associated glaucoma and steroid glaucoma but not for neovascular glaucoma (Fig. 3). The mean IOP reduction was $-3.0 \pm 5.5 \mathrm{mmHg}$ in 122 eyes with exfoliation glaucoma $(p<0.001),-4.7 \pm 7.2$ in 48 eyes with uveitis-associated glaucoma $(p<0.001)$, 
Table 2 Adverse drug reactions (ADRs)

\begin{tabular}{|c|c|}
\hline Adverse drug reactions & $n(\%)$ \\
\hline No. of patients analysed & $3058(100.0)$ \\
\hline No. of patients with ADRs & $244(8.0)$ \\
\hline No. of ADRs & 284 \\
\hline Eye disorders & $225(7.4)$ \\
\hline Conjunctival hyperemia $^{a}$ & $122(4.0)$ \\
\hline Conjunctivitis $^{\mathrm{b}}$ & $42(1.4)$ \\
\hline Blepharitis $^{c}$ & $24(0.8)$ \\
\hline Eye pruritus & $15(0.5)$ \\
\hline Punctate keratitis & $14(0.5)$ \\
\hline Eye irritation & $8(0.3)$ \\
\hline Eye pain & $8(0.3)$ \\
\hline Vision blurred & $8(0.3)$ \\
\hline Corneal erosion & $3(0.1)$ \\
\hline Eyelid oedema & $3(0.1)$ \\
\hline Abnormal sensation in eye & $2(0.1)$ \\
\hline Conjunctival follicles & $2(0.1)$ \\
\hline Lacrimation increased & $2(0.1)$ \\
\hline Corneal disorder & $2(0.1)$ \\
\hline Conjunctival erosion & $1(0.0)$ \\
\hline Conjunctival oedema & $1(0.0)$ \\
\hline Corneal epithelium defect & $1(0.0)$ \\
\hline Dry eye & $1(0.0)$ \\
\hline Eye discharge & $1(0.0)$ \\
\hline Keratitis & $1(0.0)$ \\
\hline Scintillating scotoma & $1(0.0)$ \\
\hline Foreign body sensation in eyes & $1(0.0)$ \\
\hline Eyelids pruritus & $1(0.0)$ \\
\hline Keratitis allergic & $1(0.0)$ \\
\hline
\end{tabular}

Table 2 continued

\begin{tabular}{ll}
\hline Adverse drug reactions & $n(\%)$ \\
\hline Other ADRs & $4(0.1)$ \\
Headache & $2(0.1)$ \\
Dizziness & $2(0.1)$ \\
Nausea & $1(0.0)$ \\
Bradycardia & $1(0.0)$ \\
Palpitations & $1(0.0)$ \\
Cough & $1(0.0)$ \\
Dyspnoea & $1(0.0)$ \\
Epistaxis & $1(0.0)$ \\
Dermatitis allergic & $1(0.0)$ \\
Pruritus & $1(0.0)$ \\
Urticaria & $1(0.0)$ \\
Malaise & $1(0.0)$ \\
Therapy non-responder & $1(0.0)$ \\
Intraocular pressure increased &
\end{tabular}

${ }^{a}$ Including ocular hyperemia

${ }^{b}$ Including conjunctivitis allergic

${ }^{c}$ Including blepharitis allergic

$-5.5 \pm 6.0$ in 22 eyes with steroid glaucoma $(p<0.001)$ and $-2.8 \pm 12.1$ in 21 eyes with neovascular glaucoma $(p=0.669)$.

The reduction in IOP was positively associated with the baseline IOP levels (Fig. 4). Changes in IOP were also analysed according to the treatment initiation patterns (Fig. 5). IOP was significantly reduced in all groups: $-2.8 \pm 4.2 \mathrm{mmHg}$ in 313 eyes in the "Initial monotherapy" group, $-6.7 \pm 9.4 \mathrm{mmHg}$ in 42 eyes in the "Initial combination therapy" group, $-2.7 \pm 4.6 \mathrm{mmHg}$ in 91 eyes in the "Switch from prior treatment" group, $-2.4 \pm 3.9$ in 2347 eyes in the "Add-on (only)" group and $-3.1 \pm 3.5 \mathrm{mmHg}$ in 46 eyes in the "Add-on (with other glaucoma drug)" group, 


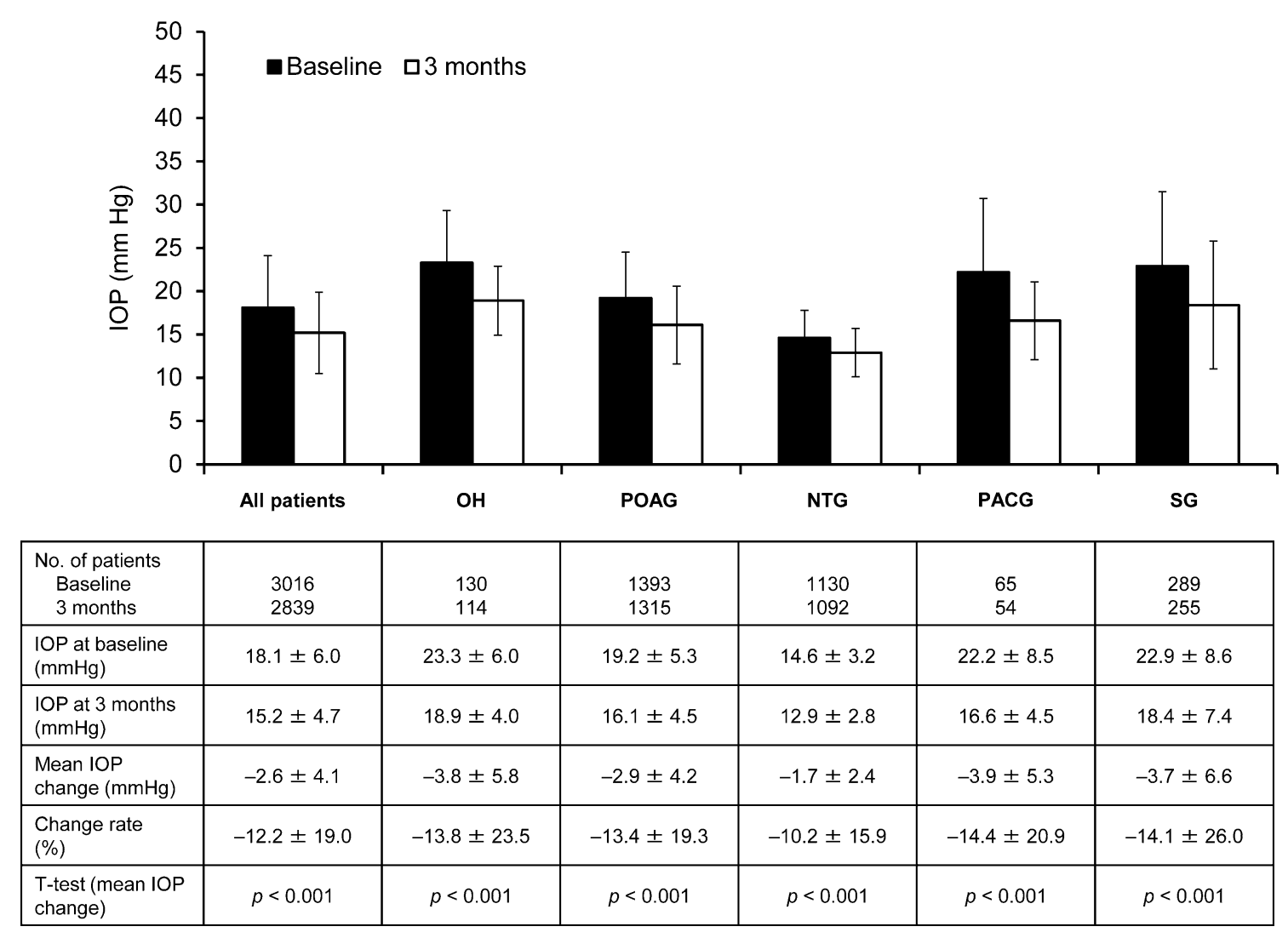

Fig. 2 Intraocular pressure changes in all patients and according to type of glaucoma. IOP intraocular pressure, $\mathrm{OH}$ ocular hypertension, POAG primary open-angle

\section{DISCUSSION}

To the best of our knowledge, this is the first large-scale (more than 3000 patients) postmarketing surveillance study to evaluate the safety and efficacy of ripasudil ophthalmic solution in Japanese patients with glaucoma or $\mathrm{OH}$. The results of this 3-month interim analysis show that ripasudil is safe and effective in reducing IOP for the treatment of glaucoma and $\mathrm{OH}$.

The main types of glaucoma for patients enrolled in this study were POAG (45.4\%) and NTG (36.9\%), which appears to be in accordance with the proportion of patients seen in the Tajimi epidemiological study conducted in Japan [19]. Although our results showed less IOP reduction in patients with NTG (associated with lower baseline IOP levels) than in those with POAG and $\mathrm{OH}$, significant IOP reduction glaucoma, NTG normal tension glaucoma, PACG primary angle-closure glaucoma, SG secondary glaucoma

and a relatively large population among the patients in this surveillance study suggest that ripasudil treatment is regarded as a useful medical treatment in the Japanese market.

Significant IOP reduction was observed in many glaucoma subtypes as seen in previous clinical trials, in which ripasudil was given as monotherapy or used in combination with latanoprost or timolol in patients with POAG or $\mathrm{OH}[14,18]$. In these studies, ripasudil monotherapy was associated with the mean change in IOP, which ranged from -3.5 to $-4.5 \mathrm{mmHg}$ [18], and when ripasudil was administered in combination with timolol or latanoprost, patients had mean IOP reductions ranging from -2.4 to -2.9 and from -2.2 to $-3.2 \mathrm{mmHg}$, respectively [14]. In previous clinical trials, evaluations were predominately based on patients with POAG or $\mathrm{OH}[14,16,18]$. In the current study, there were no restrictions on the 


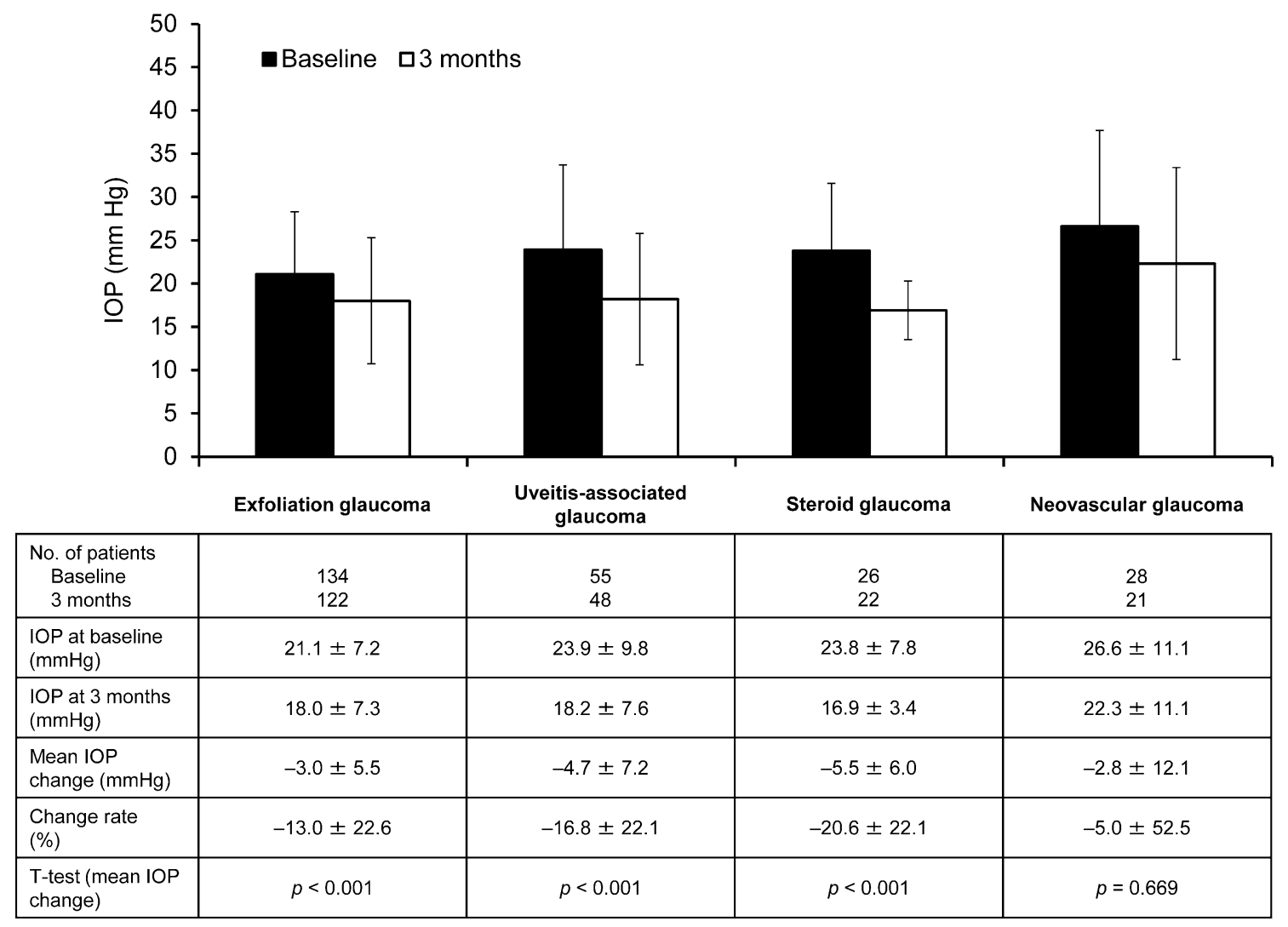

Fig. 3 Intraocular pressure changes in patients with secondary glaucoma. IOP intraocular pressure

glaucoma diagnosis; therefore, patients with NTG, PACG and SG were also enrolled. Because significant IOP reduction was also observed in patients with NTG, it is likely that a ROCK inhibitor is useful for the medical treatment of NTG.

In addition, in this large-scale surveillance study, significant IOP reduction was found in patients with exfoliation glaucoma, uveitis-associated glaucoma and steroid glaucoma. On the basis of our current results, ripasudil can be regarded as being effective in lowering IOP for these subtypes of SG. These results are in good accordance with previous work, in which significant IOP reduction was reported in patients with exfoliation glaucoma [20]. In these SG types, it is likely that activation of the RhoROCK signalling pathway in trabecular meshwork and/or Schlemm's canal endothelium contributes to the mechanisms of deteriorated aqueous outflow facility and resultant IOP elevation. In contrast, significant IOP reduction was not noted in patients with neovascular glaucoma, a condition in which fibrovascular proliferation results in deterioration of the conventional aqueous outflow. These differences in IOP responsiveness to ripasudil treatment seem to be associated with abnormalities in the conventional outflow route, which is the main target of ROCK inhibitors for IOP reduction.

Our study suggested that the IOP response was dependent on the baseline IOP level, which means that higher baseline IOP levels were associated with a larger IOP reduction. This may also explain the smaller $\Delta \mathrm{IOP}$ in patients with NTG (with slightly lower baseline IOP levels), and the larger $\triangle I O P$ in patients with SG. In the present analysis, significant IOP reductions were also observed when patients were analysed by baseline IOP levels and treatment initiation patterns. This finding suggested that ripasudil therapy was effective when used alone or in combination with other agents. 


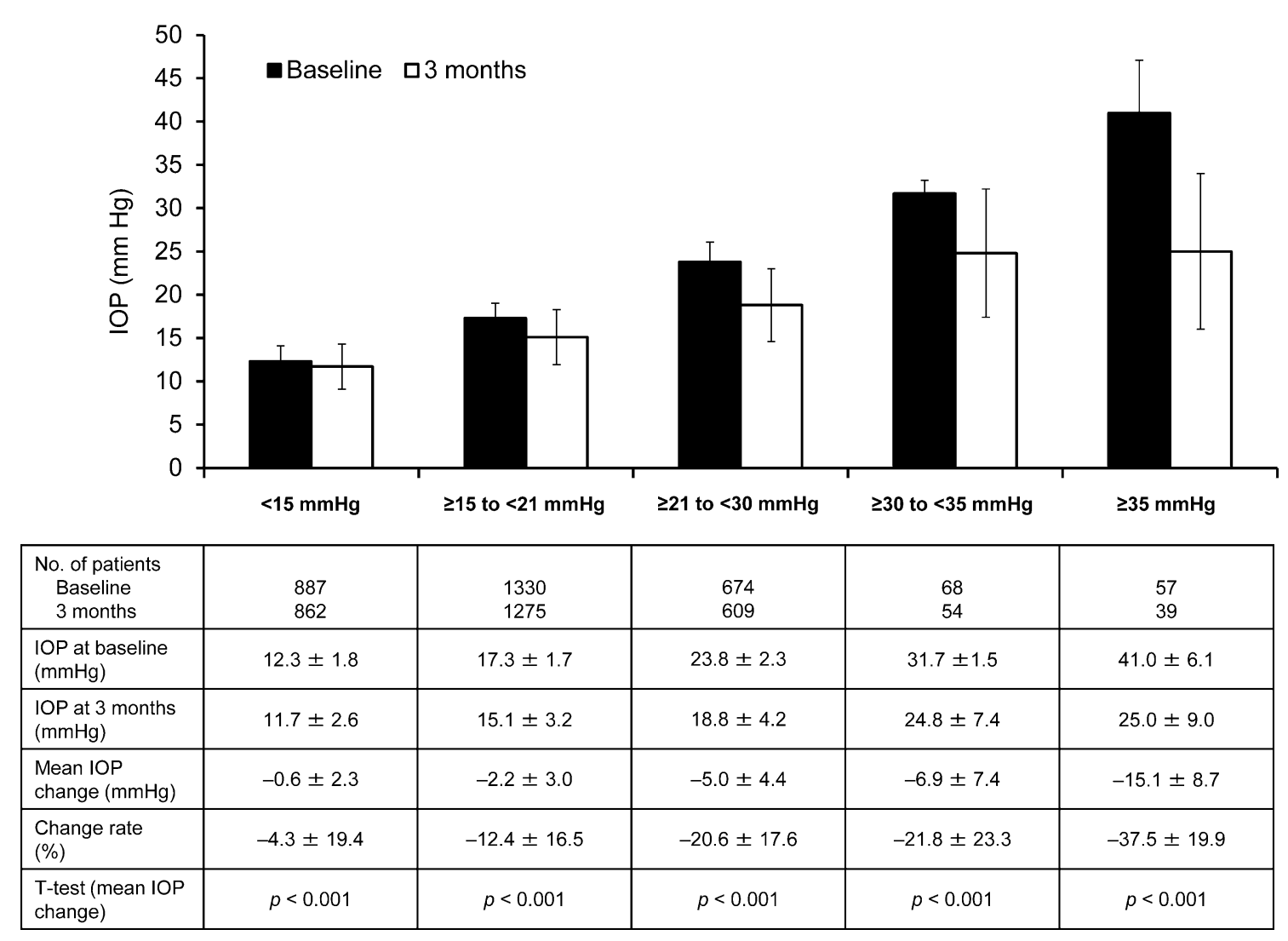

Fig. 4 Intraocular pressure changes in all patients according to baseline intraocular pressure values. IOP intraocular pressure

The incidence of ADRs was $8.0 \%$ in the current study, and no patients had serious adverse events. This incidence was much lower than the incidence of ADRs reported in previous clinical trials with ripasudil, where the overall incidence of any ADRs was 55.9-85.0\% [14, 16]. In particular, there was a much lower incidence of conjunctival hyperemia in this study $(4.0 \%)$ than in previous clinical trials (54.9-74.6\%) $[14,16]$. Conjunctival hyperemia is the most common ADR due to the vasodilatory effect of ROCK inhibitors; however, it is usually transient and resolves within $2 \mathrm{~h}$ [21]. Therefore, it is likely that any conjunctival hyperemia that developed in patients receiving ripasudil in the current study may have resolved before examination by the physician.
A major strength of the study was the large number of patients, which was reflective of the heterogeneous patient population seen in routine clinical practice. Weaknesses of the study included potential for selection bias, the lack of a control group and a relatively short follow-up period. Although the current report is limited to the first 3 months of treatment, the results may provide important information for facilitating the proper use of ripasudil. This study evaluated the safety and efficacy of ripasudil in clinical practice in patients with glaucoma and $\mathrm{OH}$. Despite the favourable short-term efficacy and safety profile demonstrated by this analysis, the results from the long-term post-surveillance study are important as glaucoma medicines are usually used for prolonged periods. 


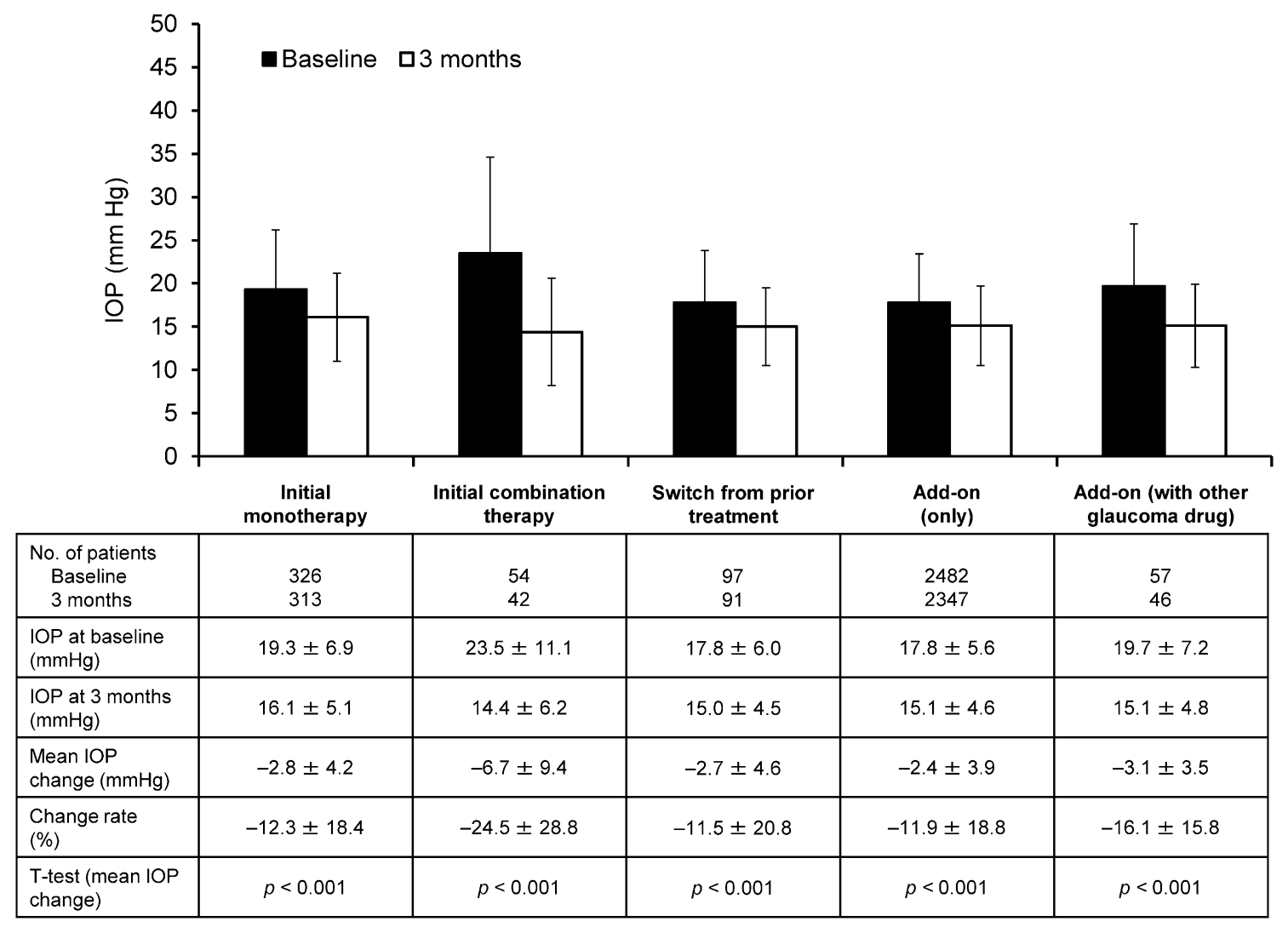

Fig. 5 Intraocular pressure changes in patients according to treatment initiation patterns. IOP intraocular pressure

\section{CONCLUSIONS}

This interim analysis showed that ripasudil has a favourable efficacy and safety profile with a low incidence of treatment discontinuation in patients with glaucoma or OH. Significant IOP reduction was observed in patients with $\mathrm{OH}$, POAG, NTG, PACG, exfoliation glaucoma, uveitis-associated glaucoma and steroid glaucoma but not for neovascular glaucoma. Overall, this 3-month interim analysis of postmarketing surveillance study suggests that ripasudil may be a promising agent for the treatment of glaucoma.

\section{ACKNOWLEDGEMENTS}

The authors thank all clinicians for their involvement and contribution to the study.
Funding: This study was funded by Kowa Company, Ltd, including the article processing changes and open access fee associated with publication. All named authors had full access to all of the data in this study and take complete responsibility for the integrity of the data and accuracy of the data analysis.

Medical writing and editorial assistance. The authors also thank Mimi Chan, $\mathrm{PhD}$, of inScience Communications, Springer Healthcare, for writing the first draft of the manuscript. This medical writing assistance was funded by Kowa Company, Ltd.

Authorship. All authors meet the International Committee of Medical Journal Editors (ICMJE) criteria for authorship for this article, take responsibility for the integrity of the work as a whole, and have given their approval for this version to be published. 
Author's contributions. All authors participated in study concept, study design, data analysis, and interpretation. The recruitment of subjects and data collection was carried out by Kowa Company, Ltd.

Disclosures. Hidenobu Tanihara has received research funding from Kowa, Santen Pharmaceutical and Senju Pharmaceutical, consulting fees from Kowa, Senju Pharmaceutical and Wakamoto Pharmaceutical, board membership fees from Santen Pharmaceutical, and honoraria for lectures from Kowa, Santen Pharmaceutical, Senju Pharmaceutical, Otsuka Pharmaceutical, Pfizer, Rohto Pharmaceutical, Wakamoto Pharmaceutical, HOYA Corporation, Mitsubishi Tanabe Pharma, Glaukos Japan, Novartis Pharma, Canon Inc., and Alcon Japan. Takahiko Kakuda is an employee of Kowa Company, Ltd. Tetsuro Sano is an employee of Kowa Company, Ltd. Takashi Kanno is an employee of Kowa Company, Ltd. Ryosuke Imada is an employee of Kowa Company, Ltd. Wataru Shingaki is an employee of Kowa Company, Ltd. Ryoji Gunji is an employee of Kowa Company, Ltd.

Compliance with Ethics Guidelines. This study was conducted as a multi-centre, open-label, prospective, non-interventional study, conducted in accordance with the Ministerial Ordinance on Good Post-Marketing Study Practice (Ministry of Health, Labour and Welfare Ordinance No. 171, December 20, 2004). The study protocol was reviewed and approved by the Japanese regulatory authority before initiation. According to the Japanese regulations, approval by the ethics committee of each participating medical institution and informed consent of individual patients are not needed for post-marketing surveillance. Therefore, this study did not undergo review by the ethics committee of the participating medical institutions or the informed consent procedure, unless such procedures were required by an individual participating medical institution.

Data Availability. The datasets generated during and/or analysed during the current study are available from the corresponding author on reasonable request.
Open Access. This article is distributed under the terms of the Creative Commons Attribution-NonCommercial 4.0 International License (http://creativecommons.org/licenses/ by-nc/4.0/), which permits any noncommercial use, distribution, and reproduction in any medium, provided you give appropriate credit to the original author(s) and the source, provide a link to the Creative Commons license, and indicate if changes were made.

\section{REFERENCES}

1. Quigley HA. Glaucoma. Lancet. 2011;377(9774):1367-77.

2. Weinreb RN, Aung T, Medeiros FA. The pathophysiology and treatment of glaucoma: a review. JAMA. 2014;311(18):1901-11.

3. Quigley HA, Broman AT. The number of people with glaucoma worldwide in 2010 and 2020. Br J Ophthalmol. 2006;90(3):262-7.

4. Jonas JB, Aung T, Bourne RR, Bron AM, Ritch R, Panda-Jonas S. Glaucoma. Lancet. 2017;390(10108):2183-93.

5. Cohen LP, Pasquale LR. Clinical characteristics and current treatment of glaucoma. Cold Spring Harb Perspect Med. 2014;4(6):a017236.

6. Mantravadi AV, Vadhar N. Glaucoma. Prim Care. 2015;42(3):437-49.

7. McKinnon SJ, Goldberg LD, Peeples P, Walt JG, Bramley TJ. Current management of glaucoma and the need for complete therapy. Am J Manag Care. 2008;14(1 Suppl):S20-7.

8. Honjo $\mathrm{M}$, Tanihara $\mathrm{H}$, Inatani $\mathrm{M}$, et al. Effects of rho-associated protein kinase inhibitor Y-27632 on intraocular pressure and outflow facility. Invest Ophthalmol Vis Sci. 2001;42(1):137-44.

9. Rao PV, Deng P-F, Kumar J, Epstein DL. Modulation of aqueous humor outflow facility by the Rho kinase-specific inhibitor Y-27632. Invest Ophthalmol Vis Sci. 2001;42(5):1029-37.

10. Tanihara $\mathrm{H}$, Inatani $\mathrm{M}$, Honjo $\mathrm{M}$, Tokushige $\mathrm{H}$, Azuma J, Araie M. Intraocular pressure-lowering effects and safety of topical administration of a selective ROCK inhibitor, SNJ-1656, in healthy volunteers. Arch Ophthalmol. 2008;126(3):309-15. 
11. Garnock-Jones KP. Ripasudil: first global approval. Drugs. 2014;74(18):2211-5.

12. Adis Insight. Ripasudil. 2018. http://adisinsight. springer.com/drugs/800028419. Accessed 8 June 2018.

13. Inoue $\mathrm{T}$, Tanihara $\mathrm{H}$. Ripasudil hydrochloride hydrate: targeting Rho kinase in the treatment of glaucoma. Expert Opin Pharmacother. 2017;18(15):1669-73.

14. Tanihara H, Inoue $\mathrm{T}$, Yamamoto $\mathrm{T}$, et al. Additive intraocular pressure-lowering effects of the Rho kinase inhibitor ripasudil (K-115) combined with timolol or latanoprost: a report of 2 randomized clinical trials. JAMA Ophthalmol. 2015;133(7):755-61.

15. Tanihara $\mathrm{H}$, Inoue $\mathrm{T}$, Yamamoto $\mathrm{T}$, et al. Intra-ocular pressure-lowering effects of a Rho kinase inhibitor, ripasudil (K-115), over 24 hours in primary open-angle glaucoma and ocular hypertension: a randomized, open-label, crossover study. Acta Ophthalmol. 2015;93(4):e254-60.

16. Tanihara $\mathrm{H}$, Inoue $\mathrm{T}$, Yamamoto $\mathrm{T}$, et al. One-year clinical evaluation of $0.4 \%$ ripasudil $(\mathrm{K}-115)$ in patients with open-angle glaucoma and ocular hypertension. Acta Ophthalmol. 2016;94(1):e2634.

17. Tanihara $H$, Inoue $T$, Yamamoto $T$, Kuwayama $Y$, Abe $\mathrm{H}$, Araie M. Phase 1 clinical trials of a selective Rho kinase inhibitor, K-115. JAMA Ophthalmol. 2013;131(10):1288-95.

18. Tanihara $\mathrm{H}$, Inoue $\mathrm{T}$, Yamamoto $\mathrm{T}$, Kuwayama $\mathrm{Y}$, Abe $\mathrm{H}$, Araie M. Phase 2 randomized clinical study of a Rho kinase inhibitor, K-115, in primary openangle glaucoma and ocular hypertension. Am J Ophthalmol. 2013;156(4):731-6.

19. Iwase A, Suzuki Y, Araie M, et al. The prevalence of primary open-angle glaucoma in Japanese: the Tajimi Study. Ophthalmology. 2004;111(9):1641-8.

20. Matsumura R, Inoue $T$, Matsumura A, Tanihara $H$. Efficacy of ripasudil as a second-line medication in addition to a prostaglandin analog in patients with exfoliation glaucoma: a pilot study. Clin Drug Investig. 2017;37(6):535-9.

21. Terao E, Nakakura S, Fujisawa Y, et al. Time course of conjunctival hyperemia induced by a Rho-kinase inhibitor anti-glaucoma eye drop. Curr Eye Res. 2017;42(5):738-42. 